Check for updates

Cite this: Chem. Sci., 2019, 10, 10417

๑ All publication charges for this article have been paid for by the Royal Society of Chemistry

Received 21st August 2019

Accepted 19th September 2019

DOI: $10.1039 / \mathrm{c} 9 \mathrm{sc} 04177 \mathrm{j}$

rsc.li/chemical-science

\section{Nickel-catalyzed hydroalkylation and hydroalkenylation of 1,3-dienes with hydrazones $\uparrow$}

\author{
Lei Cheng, Ming-Ming Li, Biao Wang, Li-Jun Xiao, Jian-Hua Xie $\mathbb{D}$ \\ and Qi-Lin Zhou (D)*
}

Transition-metal-catalyzed hydrofunctionalization of 1,3-dienes is a useful and atom-economical method for constructing allylic compounds. Although substantial progress on hydroalkylation of dienes with stabilized carbon nucleophiles has been made, hydroalkylation of dienes with unstabilized carbon nucleophiles has remained a challenge. In this article, we report a protocol for nickel-catalyzed hydroalkylation of dienes with hydrazones, which serve as equivalents of alkyl carbon nucleophiles. In addition, we developed a protocol for hydroalkenylation of dienes with $\alpha, \beta$-unsaturated hydrazones, providing a new method for the synthesis of 1,4-dienes. These hydroalkylation and hydroalkenylation reactions feature mild conditions and a wide substrate scope, and the utility of the reaction products is demonstrated by the preparation of an activator of soluble guanylate cyclase.

\section{Introduction}

1,3-Dienes are readily available commodity chemicals and are widely used in the synthesis of valuable compounds, including polymeric materials. ${ }^{\mathbf{1} 2}$ Transition-metal-catalyzed hydrofunctionalization of 1,3-dienes has emerged as a useful and atom-economical method for constructing allylic compounds, ${ }^{3}$ which are versatile building blocks in organic synthesis. ${ }^{4}$ In particular, selective addition of carbon nucleophiles such as enols and enolates to dienes (i.e., hydroalkylation of 1,3-dienes) is an efficient method for coupling two simple carbon components via $\mathrm{C}-\mathrm{C}$ bond formation. In these hydroalkylation reactions, the active catalytic species is usually a metal hydride, which reacts with the diene to generate an electrophilic metal- $\pi$-allyl intermediate that couples with the carbon nucleophile. Substantial progress has been made on palladium- and rhodium-catalyzed coupling reactions of dienes with stabilized carbon nucleophiles (Scheme 1a). ${ }^{5}$ However, the coupling of dienes with unstabilized carbon nucleophiles has remained a challenge. Recently, we developed a protocol for nickel-catalyzed regio- and enantioselective hydroalkylation reactions of dienes with carbon nucleophiles containing a single carbonyl group (Scheme 1b). ${ }^{6}$ In these reactions, the active catalytic nickel hydride species is generated by oxidative addition reaction between $\mathrm{Ni}(0)$ and an alcohol. ${ }^{7}$ To increase the utility of hydroalkylation reactions of dienes, we have been working on hydroalkylation reactions

State Key Laboratory and Institute of Elemento-Organic Chemistry, College of Chemistry, Nankai University, Tianjin 300071, China.E-mail: qlzhou@nankai.edu.cn $\uparrow$ Electronic supplementary information (ESI) available. See DOI: $10.1039 / \mathrm{c} 9 \mathrm{sc} 04177 \mathrm{j}$ with different kinds of alkyl carbon nucleophiles. Recently, Li and co-workers reported an elegant umpolung strategy that uses hydrazones as alkyl carbanion equivalents in $\mathrm{C}-\mathrm{C}$ coupling reactions with various electrophiles. ${ }^{8}$ Inspired by this work, we have now developed a protocol for nickelcatalyzed hydroalkylation reactions of dienes with hydrazones as alkyl carbon nucleophiles. In addition, when $\alpha, \beta$ unsaturated hydrazones were used, we unexpectedly develop an efficient hydroalkenylation of dienes, providing 1,4-skipped diene products with high yield and regioselectivity (Scheme 1c).

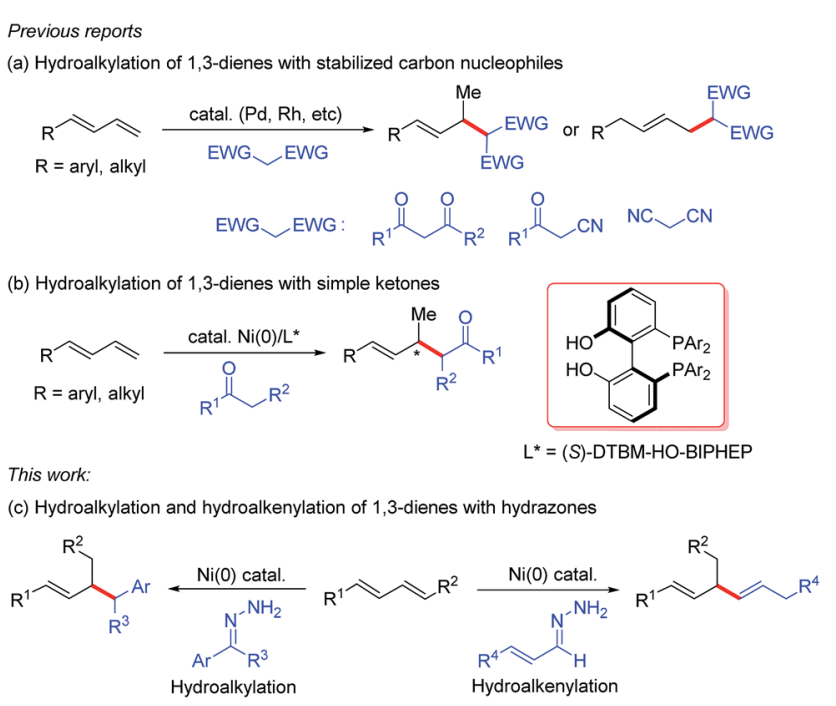

Scheme 1 Transition-metal-catalyzed allylic C-C bond formation using 1,3-dienes and carbon nucleophiles. 


\section{Results and discussion}

We began by investigating the reaction of phenylbutadiene (1a) and phenyl hydrazone (2a, 1.5 equiv.) using a Ni(COD) $)_{2} / \mathrm{DTBM}$ SEGPHOS catalyst under the previously reported hydroalkylation conditions (Table 1). ${ }^{6}$ Reaction in EtOH in the presence of catalytic ${ }^{t} \mathrm{BuOLi}$ (10 mol\%) afforded 1,2-hydroalkylation product 3a in $13 \%$ yield and 1,4-hydroalkylation product $3 \mathbf{a}^{\prime}$ in $1 \%$ yield (entry 1). In an attempt to improve the yield of $\mathbf{3 a}$ and prevent the 1,4hydroalkylation reaction, we explored various other ligands (entries 2-9). We were delighted to find that the electron-deficient ligand tris[4-(trifluoromethyl)phenyl]phosphine not only gave the best yield of 3a (85\%) but also showed high regioselectivity (1,2-/ 1,4-hydroalkylation $>20: 1$, entry 9). Control experiments showed that ${ }^{t} \mathrm{BuOLi}$ was crucial for the reaction; the yield and the regioselectivity were lower in the absence of the base (entry 10), but increasing the amount of ${ }^{t} \mathrm{BuOLi}$ to 1 equiv. resulted in no improvement in the yield or selectivity (entry 11). Screening of other alcohol solvents showed that EtOH was the best choice (compare entry 9 with entries 12-14). Finally, when the amount of the diene substrate was increased to 2 equiv., the yield of the hydroalkylation reaction increased to $92 \%$ (entry 15 ).

Under the optimal reaction conditions (Table 1, entry 15), we evaluated various 1,3-dienes $\mathbf{1}$ in reactions with aryl hydrazone

Table 1 Hydroalkylation of 1 a with $2 a$. Optimization of reaction conditions $^{a}$

\begin{tabular}{|c|c|c|c|c|c|}
\hline \multicolumn{2}{|c|}{$\mathrm{Ph} \overbrace{\substack{3 \\
\mathbf{1 a}}}^{4} \overbrace{1}^{2}+\underset{2 \mathrm{Ph}}{\mathrm{NNH}_{2}}$} & $\begin{array}{c}\mathrm{Ni}(\mathrm{COD})_{2}(10 \mathrm{~mol} \%) \\
\mathrm{L}(12 \mathrm{~mol} \%) \\
\text { additives }(10 \mathrm{~mol} \%) \\
\text { solvent, } 80^{\circ} \mathrm{C}, 8 \mathrm{~h}\end{array}$ & 3a (1,2-addition & \multicolumn{2}{|c|}{$\mathrm{e}^{+} \mathrm{Pa}_{\text {n) }}^{+1,4 \text {-addition })}$} \\
\hline Entry & Ligand & Additive & Solvent & Yield $^{b}(\%)$ & $3 \mathbf{a} / \mathbf{3} \mathbf{a}^{\prime c}$ \\
\hline 1 & DTBM-SegPhos & ${ }^{t} \mathrm{BuOLi}$ & EtOH & 13 & $13: 1$ \\
\hline 2 & DPPP & ${ }^{t} \mathrm{BuOLi}$ & EtOH & 18 & $9: 1$ \\
\hline 3 & DPPB & ${ }^{t} \mathrm{BuOLi}$ & EtOH & 65 & $18: 1$ \\
\hline 4 & DPPPe & ${ }^{t} \mathrm{BuOLi}$ & EtOH & 62 & $18: 1$ \\
\hline 5 & DPPF & ${ }^{t} \mathrm{BuOLi}$ & EtOH & 58 & $9: 1$ \\
\hline 6 & $\mathrm{PCy}_{3}$ & ${ }^{t} \mathrm{BuOLi}$ & EtOH & 33 & $3: 1$ \\
\hline 7 & $\mathrm{PPh}_{3}$ & ${ }^{t} \mathrm{BuOLi}$ & EtOH & 64 & $11: 1$ \\
\hline 8 & $\mathrm{P}\left(4-\mathrm{OMeC}_{6} \mathrm{H}_{4}\right)_{3}$ & ${ }^{t} \mathrm{BuOLi}$ & EtOH & 81 & $9: 1$ \\
\hline 9 & $\mathrm{P}\left(4-\mathrm{CF}_{3} \mathrm{C}_{6} \mathrm{H}_{4}\right)_{3}$ & ${ }^{t} \mathrm{BuOLi}$ & EtOH & 85 & $>20: 1$ \\
\hline 10 & $\mathrm{P}\left(4-\mathrm{CF}_{3} \mathrm{C}_{6} \mathrm{H}_{4}\right)_{3}$ & None & EtOH & 30 & $6: 1$ \\
\hline $11^{d}$ & $\mathrm{P}\left(4-\mathrm{CF}_{3} \mathrm{C}_{6} \mathrm{H}_{4}\right)_{3}$ & ${ }^{t} \mathrm{BuOLi}$ & EtOH & 85 & $>20: 1$ \\
\hline 12 & $\mathrm{P}\left(4-\mathrm{CF}_{3} \mathrm{C}_{6} \mathrm{H}_{4}\right)_{3}$ & ${ }^{t} \mathrm{BuOLi}$ & $\mathrm{MeOH}$ & 28 & $11: 1$ \\
\hline 13 & $\mathrm{P}\left(4-\mathrm{CF}_{3} \mathrm{C}_{6} \mathrm{H}_{4}\right)_{3}$ & ${ }^{t} \mathrm{BuOLi}$ & ${ }^{n} \mathrm{PrOH}$ & 80 & $>20: 1$ \\
\hline 14 & $\mathrm{P}\left(4-\mathrm{CF}_{3} \mathrm{C}_{6} \mathrm{H}_{4}\right)_{3}$ & ${ }^{t} \mathrm{BuOLi}$ & ${ }^{i}$ PrOH & 71 & $16: 1$ \\
\hline $15^{e}$ & $\mathrm{P}\left(4-\mathrm{CF}_{3} \mathrm{C}_{6} \mathrm{H}_{4}\right)_{3}$ & ${ }^{t} \mathrm{BuOLi}$ & EtOH & $95(92)^{f}$ & $>20: 1$ \\
\hline
\end{tabular}

${ }^{a}$ Reaction conditions: $1 \mathrm{a}(0.1 \mathrm{mmol}), 2 \mathrm{a}(0.15 \mathrm{mmol}), \mathrm{Ni}(\mathrm{COD})_{2}(0.01$ $\mathrm{mmol}$ ), ligand $(0.012 \mathrm{mmol}$ for monodentate ligand, $0.01 \mathrm{mmol}$ for bidentate ligand), additive $(0.01 \mathrm{mmol})$, solvent $(0.75 \mathrm{~mL})$ at $80^{\circ} \mathrm{C}$ for 8 h. ${ }^{b}{ }^{1} \mathrm{H}$ NMR yields of major isomer $3 \mathrm{a}$ using $1,3,5^{-}$ trimethoxybenzene as internal standard. ${ }^{c}$ Regioselectivity (ratio of 1,2- and 1,4-hydrogenation products) was determined by ${ }^{1} \mathrm{H}$ NMR analysis of reaction mixture. ${ }^{d}$ Additives: 1.0 equivalent. ${ }^{e}$ 1a $(0.2$ $\mathrm{mmol}), 2 \mathrm{a}(0.1 \mathrm{mmol}) .{ }^{f}$ Isolated yield in the parentheses. DPPP $=1,3-$ bis(diphenylphosphino)propane; DPPB $=1,4$-bis(diphenylphosphino) butane; $\mathrm{DPPPe}=1,5$-bis(diphenylphosphino)pentane; $\mathrm{DPPF}=1,1^{\prime}$ bis(diphenylphosphino)ferrocene. (2a or $\mathbf{2 g}$ ) (Table 2). Terminal dienes with para-substituted aromatic rings (1b-1f) afforded the desired hydroalkylation products in high yields (80-95\%) with excellent regioselectivity $(\geq 20: 1)$; dienes with electron-donating substituents such as OMe (1d) and $\mathrm{NMe}_{2}$ (1e) gave slightly lower yields than dienes with electron-withdrawing substituents. Terminal dienes with meta- and ortho-substituted aromatic rings (19-1i) also reacted smoothly with 2a to afford the corresponding hydroalkylation products, although diene 1g, which has two meta OMe groups, gave only a moderate yield of $\mathbf{3 g}(64 \%)$. Diene $\mathbf{1 i}$, which has an ortho Me group, showed lower regioselectivity $(10: 1)$. In addition, furyl diene $\mathbf{1} \mathbf{j}$ and thienyl diene $\mathbf{1 k}$ also worked well in the reaction with $\mathbf{2 a}$, affording good yields of the expected products with excellent regioselectivity. We were delighted to find that internal aromatic dienes 11-1r were also suitable substrates; a variety of functional groups in the internal dienes, including an ester (1n), ethers (10 and 1p), an amine (1q), and an acetal (1r), were tolerated under the reaction conditions. It is worth mentioning that the $Z / E$ configuration of the aromatic dienes had no effect on the yield or regioselectivity of the reaction (see ESI $\dagger$ ). In addition to aromatic dienes, aliphatic dienes $1 \mathrm{~s}$ and $\mathbf{1 t}$ were also examined in the reaction with $2 \mathbf{g}$ and found to afford 1,2-hydroalkylation products 3 s and $3 \mathbf{t}$, in good yields ( $80 \%$ and

Table 2 Hydroalkylation of dienes with hydrazone $2 a^{a, b}$

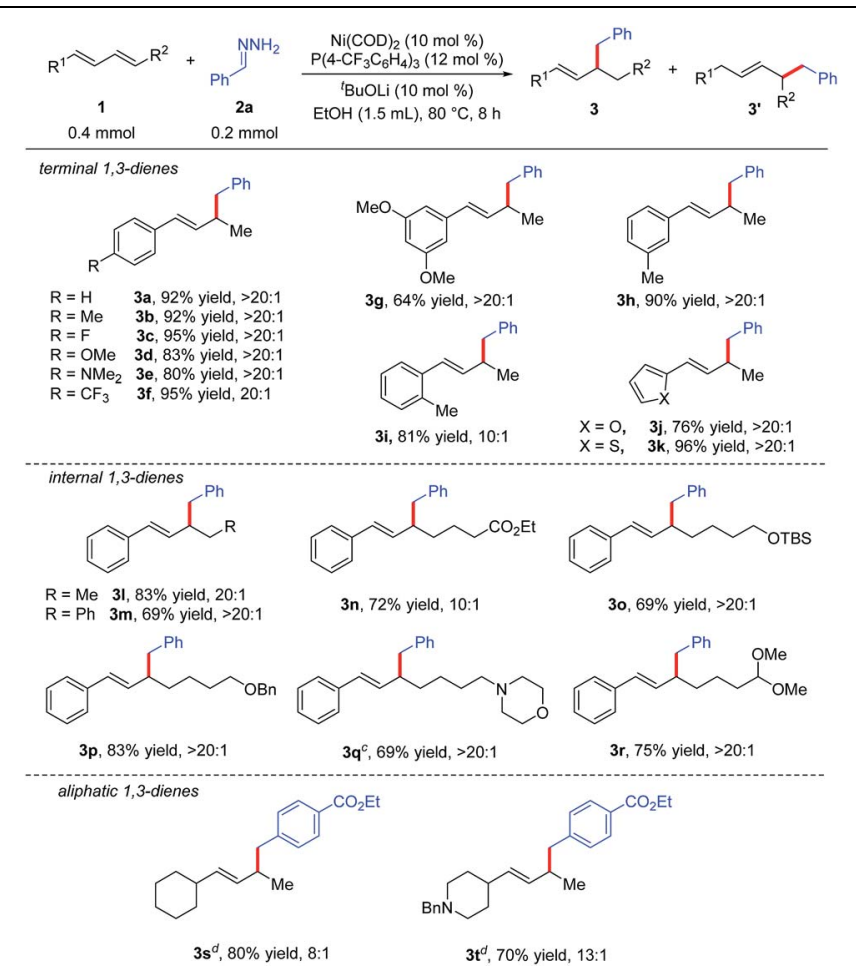

${ }^{a}$ Reaction conditions: $1(0.4 \mathrm{mmol}), 2 \mathrm{a}(0.2 \mathrm{mmol}), \mathrm{Ni}(\mathrm{COD})_{2}(0.02$ $\mathrm{mmol}), \mathrm{P}\left(4-\mathrm{CF}_{3} \mathrm{C}_{6} \mathrm{H}_{4}\right)_{3}(0.024 \mathrm{mmol}),{ }^{t} \mathrm{BuOLi}(0.02 \mathrm{mmol})$, EtOH $(1.5$ $\mathrm{mL}$ ) at $80^{\circ} \mathrm{C}$ for $8 \mathrm{~h}$. Isolated yields. Regioselectivity was the ratio of 3 to $3^{\prime}$, which was determined by ${ }^{1} \mathrm{H}$ NMR analysis of the product. ${ }^{b} Z / E$ configuration of aromatic dienes had no effect on the yield and selectivity of the reaction (see ESI). ${ }^{c} \mathbf{1}(0.2 \mathrm{mmol}), \mathbf{2 a}(0.3 \mathrm{mmol}) .{ }^{d} E$ isomer of aliphatic diene as starting material, DPPPe as the ligand. 
$70 \%$, respectively) with good regioselectivities ( $8: 1$ and $13: 1$, respectively) when the diphosphine ligand DPPPe was used.

We next examined the scope of the reaction with respect to the hydrazone substrate by carrying out reactions of various hydrazones 2 with phenylbutadiene (1a) (Table 3). Many substituted benzaldehyde hydrazones gave good to high yields, and excellent functional group compatibility was observed, demonstrating the benefit of using hydrazones as nucleophiles in this hydroalkylation reaction. For example, hydrazone $\mathbf{2 g}$, which has an ester group that would not be tolerated in reactions with organometallic reagents, gave corresponding product $\mathbf{4 g}$ in $89 \%$ yield with $>20: 1$ regioselectivity. Base-sensitive trimethylsilyl-substituted hydrazone $\mathbf{2 h}$ did not decompose under the reaction conditions. The remarkable compatibility of the reaction with substrates containing heterocycles (pyridine, quinoline, pyrrole, furan, and thiophene; 2l-2q) showed the potential utility of this protocol for the synthesis of natural products. In addition, the hydrazone derived from aromatic ketone 2r was also a viable substrate, although the reaction conditions had to be modified slightly and the diastereoselectivity was low. Note, however, that no hydroalkylation products were obtained from reactions with hydrazones derived from aliphatic ketones or aldehydes.

We also explored reactions between 1,3-dienes 1 and $\alpha, \beta$ unsaturated hydrazones 5 (Table 4). Surprisingly, a completely different hydroalkenylation product, 1,4-diene 6a, was obtained from the reaction of 3-phenylallylidenehydrazine (5a) with phenylbutadiene (1a); clearly, the double bond of 5a had migrated during the reaction. 1,4-Dienes, which are widely found in natural products and are important building blocks in organic synthesis, ${ }^{9}$ are usually prepared by transition-metalcatalyzed allylic substitution reactions with stoichiometric amounts of alkenylmetal reagents. ${ }^{10}$ The reaction between $1 \mathrm{a}$

Table 3 Hydroalkylation of diene 1a with various hydrazones $2^{a}$

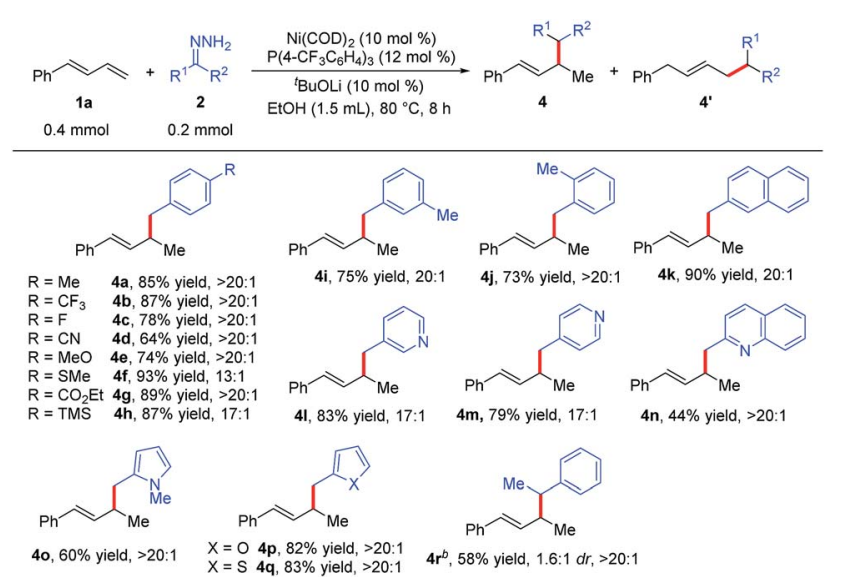

${ }^{a}$ Reaction conditions: $1 \mathrm{a}(0.4 \mathrm{mmol}), 2(0.2 \mathrm{mmol}), \mathrm{Ni}(\mathrm{COD})_{2}(0.02$ $\mathrm{mmol}), \mathrm{P}\left(4-\mathrm{CF}_{3} \mathrm{C}_{6} \mathrm{H}_{4}\right)_{3}(0.024 \mathrm{mmol}),{ }^{t} \mathrm{BuOLi}(0.02 \mathrm{mmol}), \mathrm{EtOH}(1.5$ $\mathrm{mL}$ ) at $80^{\circ} \mathrm{C}$ for $8 \mathrm{~h}$. Isolated yields. Regioselectivity was the ratio of 4 to $\mathbf{4}^{\prime}$, which was determined by ${ }^{1} \mathrm{H}$ NMR analysis of the product. ${ }^{b} \mathbf{1 a}$ $(0.2 \mathrm{mmol}), 2 \mathrm{r}(0.3 \mathrm{mmol}), \mathrm{Ni}(\mathrm{COD})_{2}(0.02 \mathrm{~mol}), \mathrm{PBn}_{3}(0.024 \mathrm{mmol})$, ${ }^{t} \mathrm{BuOLi}(0.02 \mathrm{mmol})$, EtOH $(1.0 \mathrm{~mL})$ at $80^{\circ} \mathrm{C}$ for $8 \mathrm{~h}$.
Table 4 Hydroalkenylation of dienes with $\alpha, \beta$-unsaturated hydrazones $^{a}$

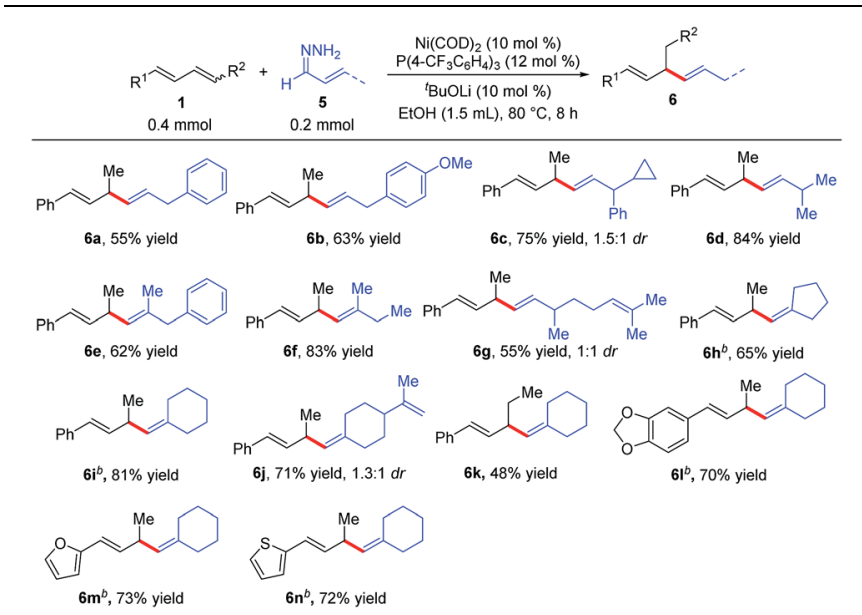

${ }^{a}$ Reaction conditions: 1a $(0.4 \mathrm{mmol}), \alpha, \beta$-unsaturated hydrazones $4(0.2$ $\mathrm{mmol}), \mathrm{Ni}(\mathrm{COD})_{2}(0.02 \mathrm{mmol}), \mathrm{P}\left(4-\mathrm{CF}_{3} \mathrm{C}_{6} \mathrm{H}_{4}\right)_{3}(0.024 \mathrm{mmol}),{ }^{t} \mathrm{BuOLi}$ $(0.02 \mathrm{mmol})$, EtOH $(1.5 \mathrm{~mL})$ at $80{ }^{\circ} \mathrm{C}$ for $8 \mathrm{~h}$. Isolated yields. Regioselectivity was determined by ${ }^{1} \mathrm{H}$ NMR analysis. ${ }^{b} 1 \mathrm{a}(0.2 \mathrm{mmol})$, $\alpha, \beta$-unsaturated hydrazones $4(0.4 \mathrm{mmol})$.

and 5a avoids the preparation of alkenylmetal reagents and can occur under mild conditions, thus providing an effective method for the construction of 1,4-dienes. ${ }^{11}$ As shown in Table 4 , a variety of substituted 1,4-dienes were synthesized by reactions of 1,3-dienes with hydrazones. $\alpha, \beta$-Unsaturated hydrazones derived from cinnamaldehyde (6a-6c and $\mathbf{6 e})$, acyclic enals (6d, 6f, and 6g), and cyclic enals (6h-6n) were amenable to this protocol, particularly noteworthy are the reactions of the natural-product-derived enals citral $(\mathbf{6 g})$ and perillaldehyde $(\mathbf{6 j})$. In addition, the internal diene $\mathbf{6 k}$, and the heteroaromatic dienes $\mathbf{6 m}$ and $\mathbf{6 n}$ also worked well, giving 1,4-diene products.

To demonstrate the utility of the protocol, we synthesized dicarboxylic acid 8, a soluble guanylate cyclase activator that is used to treat cardiovascular diseases. ${ }^{12}$ Specifically, the reaction of diene $\mathbf{1} \mathbf{u}$ and hydrazone $\mathbf{2} \mathbf{g}$ under the standard conditions afforded hydroalkylation product 7 (76\%), which could be hydrolyzed to afford desired dicarboxylic acid 8 in total $72 \%$ yield (Scheme 2). This two-step Ni-catalyzed hydroalkylation process represents a considerable improvement over the previously reported synthesis of $\mathbf{8}$, which requires multiple steps. ${ }^{\mathbf{1 2 a}}$

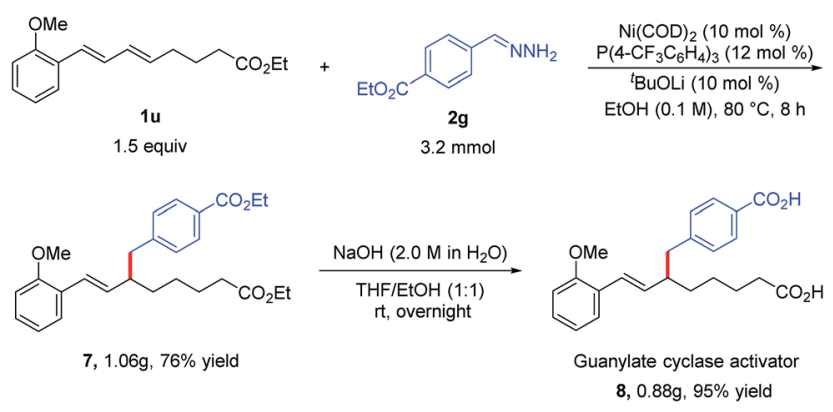

Scheme 2 Synthesis of guanylate cyclase activator 8 . 

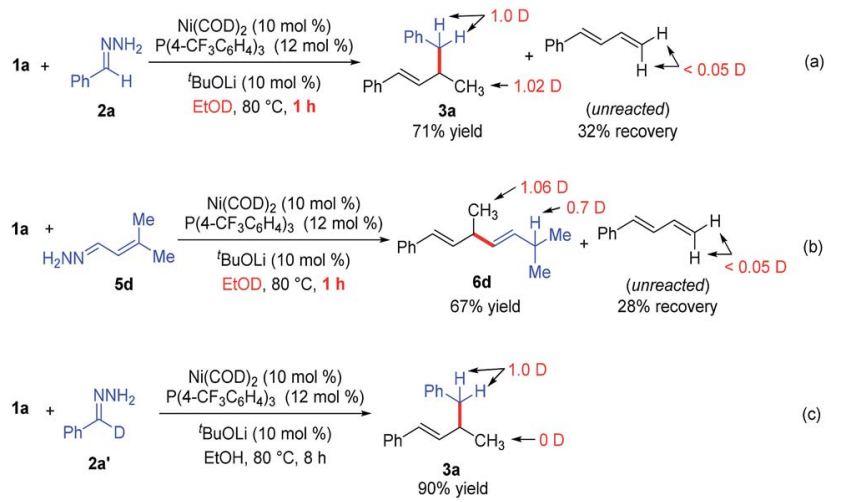

Scheme 3 Deuterium-labeling experiments.

To gain insight into the reaction mechanism, we conducted deuterium-labeling experiments in EtOD (Scheme 3a-3c). The hydroalkylation and hydroalkenylation reactions were carried out in EtOD and stop the reactions at 1 hour. In the hydroalkylation (Scheme 3a), one deuterium is incorporated into the methyl group, one deuterium into the benzyl position of product 3a. In the hydroalkenylation (Scheme 3b), one deuterium is incorporated into the methyl group, and 0.7 deuterium into the newly formed allylic position of product $\mathbf{6 d}$. Notably, the unreacted diene 1a only contains $<0.05$ deuterium in both reactions, which implies that the addition of $\mathrm{Ni}-\mathrm{H}$ bond into the diene is irreversible in the reaction. Finally, when deuterated hydrazone $2 \mathbf{a}^{\prime}$ was allowed to react with phenyldiene $\mathbf{1 a}$, deuterium was observed only at the benzyl position of product 3a (Scheme 3c), which means that the reaction did not involve cleavage of the $\mathrm{C}-\mathrm{H}$ bond at the benzyl position of hydrazone. ${ }^{13}$

On the basis of the aforementioned experimental results and previous reports, ${ }^{6-8}$ we propose the mechanism shown in Scheme 4. First, oxidative addition of EtOH to $\mathrm{Ni}(0)$ generates $\mathrm{Ni}-\mathrm{H}$ intermediate $\mathbf{A}$, which adds to diene 1a to afford $\pi$-allylnickel intermediate B. A ligand exchange reaction between $\mathbf{B}$ and the diazene anion generated from hydrazone 2a forms

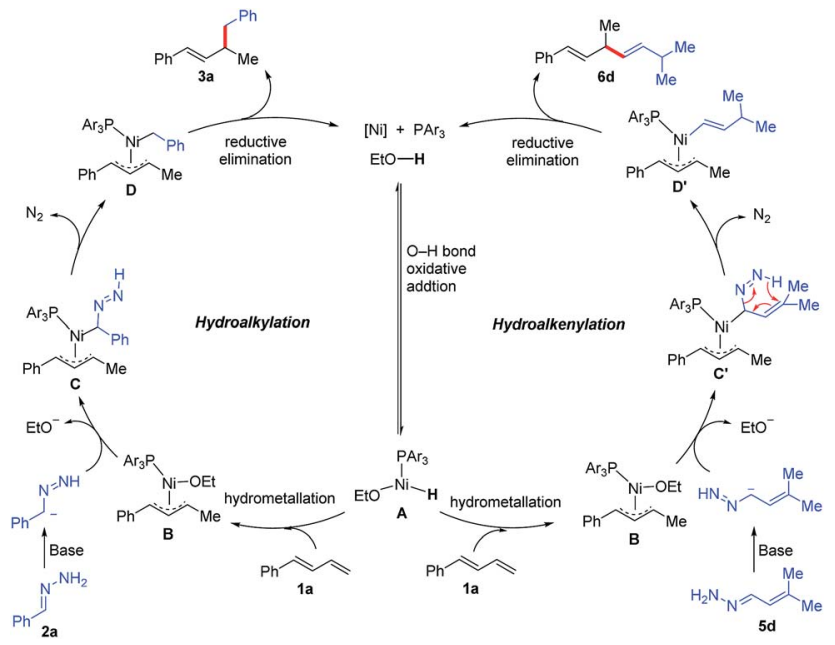

Scheme 4 A proposed mechanism. intermediate $\mathbf{C}$. In the presence of base in the protic medium, expulsion of nitrogen and protonation of the intermediate $\mathbf{C}$ occur to provide intermediate $\mathbf{D} .^{14}$ A reductive elimination reaction of $\mathbf{D}$ delivers hydroalkylation product $3 \mathbf{a}$ and regenerates the $\mathrm{Ni}(0)$ catalyst. ${ }^{15}$ Similar steps are involved in the hydroalkenylation reaction. Specifically, reaction of the diazene anion generated from $\alpha, \beta$-unsaturated hydrazone $5 \mathbf{d}$ with $\pi$ allylnickel intermediate $\mathbf{B}$ forms intermediate $\mathbf{C}^{\prime}$. Expulsion of nitrogen from $\mathbf{C}^{\prime}$ via a 1,5-sigmatropic migration gives alkenyl$\mathrm{Ni}$ intermediate $\mathbf{D}^{\prime},{ }^{14 d, 15}$ which undergoes a reductive elimination reaction to form hydroalkenylation product $\mathbf{6 d}$.

\section{Conclusions}

In summary, we have developed a protocol for nickel-catalyzed hydroalkylation reactions of dienes with hydrazones, and this protocol provides a new method for hydroalkylation reactions using hydrazones as alkyl carbon nucleophiles. In addition, we developed a protocol for hydroalkenylation of dienes with $\alpha, \beta$ unsaturated hydrazones, providing a new synthetic route to 1,4dienes. These hydrofunctionalization reactions feature mild conditions and a wide substrate scope, and the products are versatile building blocks for organic synthesis, as demonstrated by the preparation of soluble guanylate cyclase activator $\mathbf{8}$. Works on the development of asymmetric version of the reactions and exploration of their mechanisms are currently underway in our laboratory.

\section{Conflicts of interest}

There are no conflicts to declare.

\section{Acknowledgements}

We thank the National Natural Science Foundation of China, (No. 21790332, 21532003) and the "111" project (B06005) of the Ministry of Education of China for financial support.

\section{Notes and references}

1 For selected reviews on 1,3-dienes as building blocks, see: $(a)$ S. Reymond and J. Cossy, Chem. Rev., 2008, 108, 5359; (b) J.-R. Chen, X.-Q. Hu, L.-Q. Lu and W.-J. Xiao, Chem. Rev., 2015, 115, 5301; (c) M. Büschleb, S. Dorich, S. Hanessian, D. Tao, K. B. Schenthal and L. E. Overman, Angew. Chem., Int. Ed., 2016, 55, 4156; (d) M. Holmes, L. A. Schwartz and M. J. Krische, Chem. Rev., 2018, 118, 6026; (e) Y. Xiong, Y.-W. Sun and G.-Z. Zhang, Tetrahedron Lett., 2018, 59, 347. 2 For reviews on polymerization of 1,3-dienes, see: (a) L. Friebe, O. Nuyken and W. Obrecht, Adv. Polym. Sci., 2006, 204, 1; (b) G. Ricci, A. Sommazzi, F. Masi, M. Ricci, A. Boglia and G. Leone, Coord. Chem. Rev., 2010, 254, 661; (c) A. Valente, A. Mortreux, M. Visseaux and P. Zinck, Chem. Rev., 2013, 113, 3836; (d) D. Takeuchi, Stereoselective polymerization of conjugated dienes, in Encyclopedia of Polymer Science and Technology, Wiley, New York, 2013, pp. 1-25. 
3 Reviews on hydrofunctionalizations of dienes: (a) L.-B. Huang, M. Arndt, K. Gooßen, H. Heydt and L. J. Gooßen, Chem. Rev., 2015, 115, 2596; (b) E. McNeill and T. Ritter, Acc. Chem. Res., 2015, 48, 2330; (c) Z. Dong, Z. Ren, S. J. Thompson, Y. Xu and G. Dong, Chem. Rev., 2017, 117, 9333; (d) W.-Y. Ai, R. Zhong, X.-F. Liu and Q. Liu, Chem. Rev., 2019, 119, 2876; (e) D. Wei and C. Darcel, Chem. Rev., 2019, 119, 2550.

4 Applications of allylic substitution reaction: (a) B. M. Trost and M. L. Crawley, Chem. Rev., 2003, 103, 2921; (b) B. M. Trost, J. Org. Chem., 2004, 69, 5813; (c) B. M. Trost and J. E. Schultz, Synthesis, 2019, 51, 1; (d) Q. Cheng, H.-F. Tu, C. Zheng, J.-P. Qu, G. Helmchen and S.-L. You, Chem. Rev., 2019, 119, 1855.

5 For selected hydroalkylations of diene, see: (a) G. Hata, K. Takahashi and A. Miyake, J. Org. Chem., 1971, 36, 2116; (b) A. Leitner, J. Larsen, C. Steffens and J. F. Hartwig, J. Org. Chem., 2004, 69, 7552; (c) M. J. Goldfogel and S. J. Meek, Chem. Sci., 2016, 7, 4079; (d) M. J. Goldfogel, C. C. Roberts, R. S. Manan and S. J. Meek, Org. Lett., 2017, 19, 90; (e) X.-H. Yang and V. M. Dong, J. Am. Chem. Soc., 2017, 139, 1774; $(f)$ N. J. Adamson, K. C. E. Wilbur and S. J. Malcolmson, J. Am. Chem. Soc., 2018, 140, 2761; (g) S. Park, N. J. Adamson and S. J. Malcolmson, Chem. Sci., 2019, 10, 5176.

6 L. Cheng, M.-M. Li, L.-J. Xiao, J.-H. Xie and Q.-L. Zhou, J. Am. Chem. Soc., 2018, 140, 11627.

7 (a) L.-J. Xiao, L. Cheng, W.-M. Feng, M.-L. Li, J.-H. Xie and Q.-L. Zhou, Angew. Chem., Int. Ed., 2018, 57, 461; (b) L.-J. Xiao, M.-C. Ye and Q.-L. Zhou, Synlett, 2019, 30, 361.

8 (a) H. Wang, X.-J. Dai and C.-J. Li, Nat. Chem., 2017, 9, 374; (b) X.-J. Dai, H. Wang and C.-J. Li, Angew. Chem., Int. Ed., 2017, 56, 6302; (c) N. Chen, X.-J. Dai, H. Wang and C.-J. Li, Angew. Chem., Int. Ed., 2017, 56, 6260; (d) L. Lv, D. Zhu, J. Tang, Z. Qiu, C.-C. Li, J. Gao and C.-J. Li, ACS Catal., 2018, 8, 4622; (e) D. Zhu, L. Lv, C.-C. Li, S. Ung, J. Gao and C.-J. Li, Angew. Chem., Int. Ed., 2018, 57, 16520.

9 (a) M. S. F. L. K. Jie, M. K. Pasha and M. S. K. SyedRahmatullah, Nat. Prod. Rep., 1997, 14, 163; (b)
Y. Shinohara, F. Kudo and T. Eguchit, J. Am. Chem. Soc., 2011, 133, 18134; (c) P. Winter, W. Hiller and M. Christmann, Angew. Chem., Int. Ed., 2012, 51, 3396; (d) W. Tang and E. V. Prusov, Angew. Chem., Int. Ed., 2012, 51, 3401.

10 (a) N. Miyaura, T. Yano and A. Suzuki, Tetrahedron Lett., 1980, 21, 2865; (b) H. Matsushita and E. Negishi, J. Am. Chem. Soc., 1981, 103, 2882; (c) F. K. Sheffy and J. K. Stille, J. Am. Chem. Soc., 1983, 105, 7173; (d) Y. Lee, K. Akiyama, D. G. Gillingham, M. K. Brown and A. H. Hoveyda, J. Am. Chem. Soc., 2008, 130, 446; (e) K. Akiyama, F. Gao and A. H. Hoveyda, Angew. Chem., Int. Ed., 2010, 49, 419; (f) J. Y. Hamilton, D. Sarlah and E. M. Carreira, J. Am. Chem. Soc., 2013, 135, 994.

11 For reviews of hydroalkenylation of 1,3-dienes: (a) T. V. RajanBabu, Chem. Rev., 2003, 103, 2845; (b) T. V. RajanBabu, Synlett, 2009, 853; (c) G. Hilt, Eur. J. Org. Chem., 2012, 4441.

12 (a) C. Alonso-Alija, M. Heil, D. Flubacher, P. Naab, J.-P. Stasch, F. Stasch, K. Dembowsky, E. Perzborn and E. Stahl, US Pat., US 20080058314 A1, Bayer Aktiengesellschaft, USA, 2008; (b) M. Follmann, N. Griebenow, M. G. Hahn, I. Hartung, F. J. Mais, J. Mittendorf, M. Schaefer, H. Schirok, J. P. Stasch, F. Stoll and A. Stoll, Angew. Chem., Int. Ed., 2013, 52, 9442.

13 See ESI $\dagger$ for more details about the mechanism studies.

14 (a) H. H. Szmant, Angew. Chem., Int. Ed., 1968, 7, 120; (b) H. H. Szmant and C. E. Alciaturi, J. Org. Chem., 1977, 42, 1081; (c) H. H. Szmant, A. Birke and M. P. Lau, J. Am. Chem. Soc., 1977, 99, 1863; (d) R. O. Hutchins, in Comprehensive Organic Synthesis, ed. B. M. Trost and I. Fleming, Pergamon, Oxford, 1991, vol. 8, pp. 327-362.

15 The isomerization of double bond commonly occurs in reduction of $\alpha, \beta$-unsaturated hydrazones : $(a)$ R. A. Sneen and N. P. Matheny, J. Am. Chem. Soc., 1964, 86, 5503; (b) E. J. Taylor and C. Djerassi, J. Am. Chem. Soc., 1976, 98, 2275; (c) R. O. Hutchins and N. R. Natale, J. Org. Chem., 1978, 43, 2299; (d) Ref. 14d. 